\title{
Las interacciones de los docentes y alumnos de Secundaria
}

\author{
Lilia Rey Chávez \\ Profesora investigadora \\ Centro de Investigación y Docencia
}

\section{Resumen}

$\mathrm{E}$

1 presente artículo se deriva de un proyecto de investigación apoyado por el Fondo Mixto Conacyt-Gobierno del Estado de Chihuahua. El estudio cualitativo basado en una experiencia etnográfica permitió rescatar algunas dinámicas relacionadas con el trabajo en el salón de clases en ocho escuelas secundarias de la entidad. De manera concreta, en este artículo se presentan los resultados que se refieren a las relaciones e interacciones que se establecen entre el docente y los estudiantes en las aulas de las escuelas visitadas.

Palabras clave: interacciones, prácticas educativas, relaciones de poder, autoridad, micropolítica.

\section{Introducción}

Con este trabajo se pretende hacer una revisión de la práctica educativa de los docentes de secundaria para caracterizar las relaciones que establecen con los estudiantes.
Una de las particularidades del trabajo que se lleva a cabo en el aula es que el profesor realiza varias actividades de manera simultánea, que se agrupan en torno a ciertas rutinas: pasar lista, revisar tareas, organización de equipos, revisión y desarrollo de proyectos, exposiciones en el pizarrón y ejercicios colectivos, dictado, lecturas comentadas, ejercicios en los libros y cuadernos, y algunas rutinas de evaluación. Esta última actividad implica a su vez una serie de estrategias tales como el registro de las participaciones de los alumnos, la revisión de cuadernos, ejercicios y materiales de trabajo, preparación para los exámenes, aplicación y revisión de los mismos, reportes de calificaciones, entre otras. Estas son el tipo de estrategias que enmarcan las relaciones de estudiantes y docentes, que desde el punto de vista político tipificamos como relaciones de poder, donde hay evidencias que confirman el papel dominante del docente sobre los alumnos, aunque también se puede apreciar que los estudiantes no se encuentran indefensos ante las actitudes autoritarias, y buscan causes para 
REVISTA DE INVESTIGACIÓN EDUCATIVA DE LA REDIECH N. 3

enfrentar la autoridad encarnada, en este caso, en el profesor.

\section{Estrategia metodológica}

En lo que se refiere a la perspectiva metodológica, para este estudio, el equipo de investigación optó por un estudio etnográfico "que consiste en describir y narrar, desde la experiencia de haber estado allá, la cultura de una localidad, para poder inscribirlo en el registro consultable de la creaciones humanas" (Geertz, citado por Rockwell, 2009: 151).

Uno de los criterios del trabajo etnográfico, consiste en exponer, conservar y respetar los textos, y los discursos que subyacen de las relaciones particulares de los sujetos de la localidad donde se hizo el estudio (Rockwell, 2009). De esta manera, en el presente estudio se van encontrar, textos, citas abundantes y densas, que tienen el sentido de preservar la voz de los sujetos que colaboraron en el estudio.

Así, a la par de los registros de observaciones y entrevistas, se realizó la transcripción e interpretación de estos textos, con la finalidad construir categorías de análisis a partir del material empírico, en este sentido el análisis cualitativo requiere un procedimiento insustituible, el trabajo sobre los textos producidos en el campo: leer, releer y releer sobre los registros, interpretarlos desde distintos ángulos, anotar $\mathrm{y}$ anotar sobre anotaciones, relacionar, dudar y volver a relacionar, escribir textos descriptivos preliminares, romperlos y escribirlos de nuevo, todo ello hasta encontrar cómo encajan algunas piezas del rompecabezas (Rockwell, 2009).

La etapa del trabajo de campo se concretó de enero a diciembre de 2010; se eligieron ocho escuelas secundarias -cuatro generales y cuatro técnicas- de las siguientes localidades: Chihuahua, Juárez, Parral, Cuauhtémoc y San Juanito.

\section{Resultados}

Como producto de las observaciones realizadas en las ocho escuelas secundarias, encontramos varios elementos en común en las prácticas de los profesores que colaboraron en esta investigación, independientemente de la materia que impartan. Una de las más destacadas es una preocupación constante por el orden y la disciplina en el salón de clases. Es importante señalar que no se trata de una tipificación o estandarización de los procesos sino de la descripción de algunas estrategias que comparten los docentes motivo de estudio,

El orden es un elemento muy importante para las instituciones visitadas, de él depende su prestigio y simbólicamente representa el éxito tanto para la escuela como para el docente, un docente que es capaz de mantener a los estudiantes disciplinados, trabajando en orden y en un ambiente silencioso, tiene un reconocimiento social importante. Henry (citado por Sandoval, 1975: 265) dice que "la primera lección de un niño tiene que aprender cuando llega a la escuela es que las lecciones no son lo que parecen. Luego tiene que olvidar esto y actuar como si lo fueran". Al estudiante desde que ingresa se le dan a conocer el reglamento de la escuela y una serie de normas de comportamiento no necesariamente escritas que tiene que acatar, de lo contrario hay consecuencias, tiene que enfrentarse a las sanciones como reportes, citatorios a los padres de familia, suspensiones, o en casos extremos el retiro definitivo de 
la institución. Estas normas son relativas, cada escuela tiene diferentes criterios y reglamentaciones, y en el salón de clases dependen del docente en turno, tal como se evidencia en el siguiente testimonio:

Bueno yo pienso que un salón con disciplina es un salón con éxito, por ejemplo yo soy una persona estricta, sin embargo en el desarrollo de la clase sí nos estamos riendo, o sea, a veces hago bromas para que se interesen en lo que estoy hablando, pero ellos saben que es con orden, a mí no me gusta que se estén levante $y$ levante o saliéndose como me ha tocado ver en otras clases, que los alumnos están en la puerta, que se están aventando basura, que se estén gritando, o sea, ellos saben perfectamente que a mí todo eso me molesta y yo les digo que es por su bien, que todos debemos ser disciplinados, entonces en ese aspecto como la clase de matemáticas es estar hablando entre ellos mismos en equipo, tampoco puedo tener una disciplina al $100 \%$ pero por decirlo así, es un relajo bien organizado, sí se escuchan cosas y todo, pero es porque ellos tienen que discutir de los problemas que están resolviendo (Docente: 9:129;2119:2134)

Los estudiantes (A) también fijan su posición frente a actitudes que ellos consideran injustificadas o arbitrarias:

AA: -Sí es bien fea, es que a mí me regaña por cualquier cosita por cualquier cosita así, por la más mínima... estoy escribiendo: "esa pluma no"... es... "salte", a todo mundo ha sacado del salón así.

AA2: - Ya porque uno se ríe sola, un día yo me estaba riendo sola [...] es más ni estaba hablando me estaba riendo, porque... por nada, porque estaba viendo para afuera se cayó una niña... "que se salga" me dijo... a bueno pues...

AO1: - En veces la maestra me cae muy mal la maestra, porque ofende mucho a los alumnos, les dice sus verdades.

AO2: - También ofende mucho a los obesos [...]

AA1: - A una niña [por obsesa] no la sentó en una silla sino la puso en una mesa.

AO3: - también no te gusta, porque [...] un día estaba pintando y me dijo: "No trabaja" y me aventó el borrador [todos se ríen]

AO1: - le dijo que iba hacer una carrera de 100 metros... aja. Y luego le dijo "perdón, ni a eso llega" le dijo así, las ofendía mucho, también cuando estaba "J" la ofendía mucho porque "es tan pobre que no puede comprar un qutip, para lavarse las orejas" [...] (Alumnos: 2:48; 803:814 2:50; 832:847).

Esta conversación entre el investigador (I), un prefecto $(\mathrm{P})$, y un docente $(\mathrm{M})$, que se dio de manera casual en los pasillos, ilustra sobre el alcance que puede tener la aplicación de las normas escolares:

I: - ¿Y a cuántos despidieron de la escuela?

P3: - A cinco [...].

I: ${ }_{i}$ Eso se hace de vez en cuando?

P3: - Cada cierto período. Se checa la frecuencia de reportes [...].

P3: - Se escogieron como cuarenta que andan mal, pero salen cinco. Ya mañana se les va a decir. No podemos echarlos a todos.

M23: - No, pues nos quedamos sin alumnos [...]

P3: - Se va a hablar con los padres de fa-

(n)

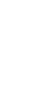


milia. Hay muchos que tienen bastantes reportes [...] Pero es que se debería ir corrigiendo bimestre por bimestre para que no se llegara a esto. Ya al final se les ha acumulado si no se atienden antes [...] Se necesita que el maestro ponga cuidado para hacer que el alumno ponga atención y no reportarlo nada más porque sí. A veces los maestros llegan enojados y son poco tolerantes. Por ejemplo, ese día agarra a alguno y lo reporta. Todos son rescatables, si los maestros se ocuparan más no habría esto [...] En la otra escuela donde trabajaba, no dábamos de baja a los alumnos. A todos los que tenían algún problema, se les decía, "va a venir el sábado de tal hora a tal hora, para hacer limpieza", o si andaban mal, para hacer retroalimentación. Y si no viene a cumplir los damos de baja, pero sí iban. [...] Tenían trabajo especial para los alumnos que iban retrasados (Conversación: 26:552; 4754:4929).

Uno de los mecanismos de control más socorridos es la restricción del movimiento en los estudiantes. Hay al menos tres formas de restricción del movimiento en el salón de clases: la que se impone a los alumnos cuando se les impide levantarse de sus lugares de manera arbitraria, es decir como un acto puro de autoridad; la que se determina a través del tipo de actividades que van a desarrollar: leer en silencio, responder un cuestionario, en el caso de actividades que requieran de la colaboración entre estudiantes, la interacción puede reducirse solo a los integrantes de los equipos; y finalmente la que imponen las condiciones físicas de las aulas y el número de estudiantes, en espacios muy reducidos y sobrepoblados los alumnos prácticamente tienen que saltar unos encima de otros para poder moverse. En el registro que se presenta a continuación se ilustran algunas de estas acciones:

El docente no ha llegado y el grupo está a cargo del prefecto $(\mathrm{P})$.

P: - póngase hacer algo... un trabajo que tengan pendiente o los pongo a trabajar yo...

Grupo: -nooooo...

P: -la maestra no está muchachos... en silencio ¿eh? [Es un grupo de 29 alumnos]

Ao: - ¿puedo salir al baño...

P: -No, no hay gafetes, no pueden salir sin gafete [P está en el estrado, una niña recarga la espalda en su mochila y apoya la cabeza en la pared mirando hacia la nada, algunos sacan sus cuadernos y los hojean]

Aa: - ¿cuánto sacaste?...

Ao: - yo ocho...

Aa: - yo seis [risas de ambos]

Aa: - ay no le entiendo a esto [intercambia los cuadernos con su compañera "P" pasa a los lugares para supervisar el trabajo que cada quien está realizando].

Ao: - ¿puedo ir con él para preguntarle algo? [Pide permiso a "P" para levantarse de su lugar, "P" asiente con la cabeza, el estudiante se dirige al otro extremo del salón, hace su consulta y regresa rápido]...

Ao: - Shhh...

P: - ¡Eih! [todo el grupo guarda silencio]...

Aa: - ¡Ay! Que silencio

["P" se acerca para conversar conmigo, los alumnos comienzan a alzar la voz, "P" reacciona]

P: - van a hacer los números romanos del uno al 400 ... 
Ao: - y eso qué tiene que ver...

Aa: - no estamos en primaria... [...]

P: - ya, en silencio... voltéate para allá, y usted... [le pide a un estudiante que salga del salón, mientras le dice... "aquí no vas andar con palabritas"]

Ao: - ¿qué le dije?...

P: -allá afuera te lo voy a decir... [lo acompaña la puerta y regresa]... ¿quién sigue? [Silencio total] (Observación: 3:41; 337:379).

Como ejemplos podemos citar los gafetes que se usan en las escuelas como pasaporte para que los estudiantes puedan salir al baño de manera ordenada, en algunos casos es necesario solicitar al docente el gafete, en otros casos éstos se encuentran a disposición de los estudiantes y pueden usarlos libremente. Otro recurso para llamar la atención de los grupos que se observó en algunos docentes durante nuestra estancia consiste en levantar el brazo para solicitar la atención de los alumnos:

Comienza la clase, hay mucho ruido y " $\mathrm{M}$ " levanta la mano para pedir silencio mientras un joven golpea a otro para que le entregue su mochila, la maestra se mantiene en silencio con el brazo en alto. [...] No siempre la petición de silencio viene del docente, en algunos casos son los alumnos quiénes la solicitan y el procedimiento es exactamente el mismo].

M: - gracias [baja el brazo y todo el grupo la imita] aquí están sus pases de salida para que vayan a baño, acabo de terminar la clase de geografía y les pido que recojan los papelitos, señorita usted me va a ayudar... tome una nadita de pinol para limpiar las bancas que están rayadas ["A" pide permiso para que otro alumno quien tiene que salir a atender algo pueda ausentarse]

Es decir, a la par de actitudes autoritarias encontramos también formas intermedias para disminuir la presión entre estudiantes y docentes. El salón de clases es un espacio político en el que se establecen relaciones de poder y asimetrías, por tanto hay un proceso continuo de enfrentamiento pero también de negociación. Hoyle, (citado por Ball, 1982:18), define la micropolítica como "las estrategias con las cuales los individuos y grupos que se hallan en contextos educativos tratan de usar sus recursos de poder e influencia a fin de promover sus intereses", es decir, para desarrollar el trabajo se requiere de diálogo y consensos, los contendientes miden su fuerza y en función de ello establecen sus posiciones. En este sentido Ball, (1989), afirma que "la vida escolar se sitúa dentro del orden negociado [...], una construcción centrada en contrastes, arreglos, acuerdos y reglas [...] la negociación es el producto de los conflictos entre el personal por mediación de las diferencias de poder que existen en la estructura de la organización". Por lo tanto hay una tensión política permanente que a veces resulta en la imposición o por el contrario en mecanismos que permiten relajar el ambiente.

Planteemos el escenario político en el salón de clases: por un lado tenemos al docente investido de una autoridad que podemos ubicar en tres niveles: la autoridad deóntica, es decir aquella que deviene de la norma; la autoridad epistémica, la que da el conocimiento; y finalmente la autoridad que tiene un adulto sobre el niño o adolescente, solo por el hecho de serlo.

Por otra parte tenemos al estudiante cuyos recursos están dados en función de: a) su 
origen social, donde los extremos suelen ser, aunque por distintas razones, los más proble; máticos; b) de la energía propia de la juventud; y c) por la fuerza del número, los grupos numerosos suelen ser un dolor de cabeza para cualquier profesor, un docente comenta al respecto: "a un grupo de 30 alumnos lo puedo educar, a un grupo de 40 lo cuido, con un grupo de más de 50 yo me cuido de ellos" (1:609; 3602:3603). Aunque la asimetría es muy evidente, con estos recursos el estudiante tiene posibilidades de retar al poder establecido. Ante la autoridad del docente -no en todos los casos podemos hablar de autoritarismo-, los estudiantes despliegan una serie de estrategias que les permiten eludir y en ocasiones neutralizar las acciones y el poder de los profesores:

El docente " $M$ " levanta la mano y dice: "vamos a comenzar", un alumno suena la butaca cada vez más fuerte y comenta que no ha hecho ninguna entrevista $y$ finge que se la hace a su compañera. Ao: - para saber del pasado: ¿cómo se conocieron? [los estudiantes que están cerca ríen, M le llama la atención. Los alumnos siguen riendo, una alumna lo hace a carcajadas] M: - ustedes llevaron a cabo una entrevista. Aa: - ¿una encuesta es una entrevista? M: - estamos hablando mucho... Ao: - ¡ah! ya recuerdo entrevisté a mis abuelos para saber cómo eran las cosas en su tiempo... [...] M: —cámbiese de lugar. Aa: -estamos en exámenes no puede encargar tarea. [Todos ríen] M: - lista de nombres o personajes a quienes ustedes quisieran entrevistar... Aa: - a la maestra de español [vuelven a reír]. M: $-\mathrm{y}$ con qué finalidad la harían y vamos a planear la entrevista, voy a nombrar los equipos, todo el que hable tiene que exponer. Mañana adquirimos un rol, que no hemos tenido: relator o vocero, jefe de equipo, cronometrista, todos tendrán un rol diferente [...] 17:437; 207:241).

La carga impositiva de la autoridad docente es reconocida por los alumnos pero, como vimos en el ejemplo anterior, éstos no asumen esta condición de manera contemplativa, es decir, no están totalmente inermes ante los profesores, y por tanto, invariablemente despliegan mecanismos defensivos que les permiten contrarrestar este poder e implantar cierto nivel de dominio, el que desde luego los docentes tratan a su vez de neutralizar a través de diversas estrategias.

Por otra parte, los estudiantes aprecian a los docentes que se acercan a ellos y atienden el lado humano del proceso educativo.

A1: -Bueno para mí una buena maestra son los que te explican bien las cosas y los que te ayudan... Sí, por ejemplo para mí una buena maestra es la que se toma el tiempo, que tenga paciencia, como ya me cansé de juzgar a los maestros verdad, bueno pues sí en parte sí tienen razón verdad, la maestra de historia [...] se desespera un resto y que ayyyyyyyyyy porque no aprendes y te avienta lo primero que ven y como la de mate se toma su tiempo "hay niña aprende"... no que aprende porque aprende, o sea se toman su tiempo y... [...]

A3: - Además de que sepa enseñar que te deje el conocimiento grabado de alguna forma que lo que ella te dijo tú te acuerdes y aparte que aprenda de sus experiencias porque una buena maestra como se dice, siempre va aprendiendo de lo que va pasando en la escuela, eso es para mí una buena maestra alguien que 
te deja... AA: - Este para mí es una persona que nos trata así, como ayudarnos para salir adelante así (Alumnos: 2:59; 936:964).

Curiosamente los estudiantes también saben reconocer el trabajo de los docentes autoritarios cuando está respaldado por una sólida preparación, o lo que hemos llamado una autoridad epistémica, los estudiantes valoran o reconocen a los profesores que dominan su materia y les aportan en sus clases. En estos casos lo que hace la diferencia no es si son estrictos o no, sino lo que saben.

A1: - La maestra de física es la maestra "C", pero es... este... bien estricta en veces, no deja de hacer cosas, pero es más dinámica su clase y la otra maestra de [la otra materia] casi no hace nada y le preguntamos algo y no nos sabe responder bien $[\ldots]$

A4: - O sea, por ejemplo la maestra de física, esa maestra sí nos regaña pero normal, es que ella hace lo que es lo normal, o sea si nos deja hacer todo...

A6): - Lo que es el reglamento con ella, no hay problema... y sabe mucho, nos dicta sin libro... así nomás... es muy estricta pero... (Alumnos: 4:19; 634:722).

Estos datos expresan las reflexiones reveladores de los estudiantes, reconocen al docente, aun con posturas autoritarias, con los reglamentos establecidos en el aula, pero los respetan porque de ellos aprenden; asimismo desdeñan las posturas de profesores que no les ofrecen conocimiento, por lo tanto sus reglas también las minimizan. Estos resultados señalan que aún con la complejidad del quehacer educativo de los docentes de secundaria, es reconocida su labor.

\section{Conclusiones}

Se distinguen las reglas impuestas a través de la institución, las que se establecen en el aula y aquéllas implícitas, pero que tienen igual o mayor peso en la dinámica de las aulas. Estas se configuran por los sujetos principales en el aula: docentes y estudiantes.

Se encontraron algunos casos con posturas autoritarias por parte de los docentes, y una evidente asimetría en cuanto al poder que tiene el profesor sobre los alumnos; se observó que éstos no están completamente indefensos frente a las prácticas represivas, de una manera $\mathrm{u}$ otra encuentran formas de retar al poder formalmente establecido. En casos concretos se evidencian actitudes intermedias para tener un equilibrio y minimizar la presión entre docentes y estudiantes.

Así también, la información manifiesta cómo los estudiantes reconocen a la o el profesor autoritario, cuando se respaldan con los saberes, es decir, el aprendizaje obtenido, pero más aún cuando se le suma la sensibilidad para escuchar a los alumnos.

\section{Bibliografía}

Ball, Stephen J. (1989). La micropolítica de la escuela: Hacia una teoría de la organización escolar, Editorial Paidos, Barcelona; México, pp. 18

Foucault, Michel (2001). Vigilar y castigar: nacimiento de la prisión, Editorial Siglo XXI, México, pp. 201.

SEP (2006). Plan de estudios. Secretaría de Educación Pública, Segunda Edición, México, p. 15 y 47.

Rockwell, E. (2009). La experiencia etnográfica. Historia y cultura en los procesos educativos.

Sandoval, F. E. (2000). La trama de la escuela secundaria: institución, relaciones y saberes. Ediciones Centro de Estudios sobre la Universidad: Plaza y Valdés. México, pp. 265. 
